\title{
EL ARTE COMO PRELUDIO DE LO TERRIBLE
}

\section{ART AS A PRELUDE TO THE TERRIBLE}

Federico Sagaspe / federico_sag@yahoo.com.ar Facultad de Artes. Universidad Nacional de La Plata. Argentina

Recibido: 8/3/2020

Aceptado: 13/6/2020

\section{RESUMEN}

El artista indaga los abismos, los límites de su existencia y, desde allí, procura traer al plano de lo decible sus anhelos, sus deseos, aquello que lo angustia, que lo horroriza. Entre esos límites que distingue e inquiere, descubre la posibilidad de morir como irrebasable; percepción que, en su cotidianeidad, se le oculta. La producción y la experiencia estética — liberadora del tiempo para algo en el que regularmente convivimos-otorgan al existente humano la viabilidad de develar su propia posibilidad de morir, su existencia como temporalidad; y, luego, revalorizar cada instante como único e irrepetible en la responsabilidad de tener que elegirse, invariablemente, en su ser hasta la muerte.

\section{PALABRAS CLAVE}

Arte; tiempo; finitud; experiencia estética

\section{ABSTRACT}

The artist investigates the abysses, the limits of his existence, and, from there, he tries to bring to the plane of the sayable his desires, his desires, that which distresses him, that horrifies him. Between those limits that he perceives and inquires, he discovers the possibility of dying as irrebatable; which, in his daily life, is hidden from him.Production and aesthetic experience -liberating time for something in which we regularly live together - give the existing human the viability of revealing his own possibility of dying, his existence as a temporality; and then, revaluing each moment as unique and unrepeatable in responsibility of having to choose, invariably, in your being until death.

\section{KEYWORDS}

Art; time; finiteness; aesthetic experience 
A lo largo de la historia, el arte aparece como una construcción hecha por el género humano; para su interrogarse, para su erigirse. Al posar el individuo su mirada sobre los abismos, sobre aquello que lo excede, sobre lo indecible, sobre aquello que no puede dominar ni conocer, aquello que lo angustia, procura afanosamente traerlo al plano de lo decible, de lo experimentable, a través de lo simbólico de la ficción. De esta manera, consigue la persona acercarse, conocer(se) y dar cuenta de aspectos de su existencia que, de otro modo, permanecerían inaccesibles.

El existente humano, como ser en el mundo, es proyecto, posibilidad. Siempre está por ser, afrontando la responsabilidad de tener que elegir - y elegirse- entre los posibles que se despliegan desde su situación. En este sentido, en la experiencia estética, el ser humano halla la oportunidad de habitar el mundo de la obra como propio; y, desde allí, alcanza a develar una posibilidad para sí, que, en su cotidianeidad, no le resulta accesible.

Parafraseando a Marcel Proust [1927] (1994), podríamos decir que la obra de arte no es más que una especie de instrumento óptico que le permite al lector discernir aquello que, sin la obra, no hubiera podido ver de sí mismo. En consecuencia, la creación artística sobresale como una creación humana que participa y ampara a la persona en el hacer de su existencia.

Dentro de todos los posibles que constituyen al existente humano, el único que aparece como ineluctable e irrebasable es la posibilidad de morir. La vida, el proyectarse, se da indefectiblemente entre la demarcación temporal del nacimiento y de la muerte. Esta limitación que supone el morir, la angustia que deviene del reconocerse finito, supo ser vehiculizada desde la creación artística a lo largo de los tiempos. No como analgésico ni para quitar pesares, no como promesa de salvación; sino como esfera de producción y como experiencia humana a partir de la cual se nos devela, de un modo privativo, nuestra temporalidad, nuestra existencia siempre abierta, nuestra posibilidad más propia, la inevitabilidad del finar. Por tanto, a través de la bella representación de aquello que nos angustia, la obra de arte nos interpela acerca del tiempo, acerca del valor del instante, acerca de lo irrepetible de cada momento, de cada experiencia y de cada mirada, en nuestro ser proyecto hasta la muerte. 


\section{LA EXPERIENCIA DE LA TEMPORALIDAD EN EL ARTE}

El arte aparece en la historia como una construcción humana y humanizante. Una producción simbólica que le permite a la persona indagar lo indecible, explorar sus deseos —como tales, nunca totalmente consumados- y sus miedos; en tanto se erige en un mundo - con sus enigmas y contingencias- que lo expone a las limitaciones intrínsecas de su humanidad. Allí donde la palabra no llega, allí donde el lenguaje articulado se vuelve estéril; allí donde el asombro se junta con las situaciones límites, allí emerge la creación artística como creación humana que le permite al individuo contemplar los abismos y traer aquello al plano de lo decible, a través de lo simbólico de la ficción. Ese es su dominio privativo, indagar lo posible y desocultar lo que otras esferas no pueden.

El arte consigue introducirse por las fisuras de lo establecido, de las zonas de confort y así; fractura tanto los conceptos imperantes como los hábitos perceptuales. Pero no para romper sin más, sino para reconstruir un horizonte más vasto de posibilidades. Incluso, en incontables ocasiones, en este mirar más allá, ha sabido la creación artística anticipar muchos interrogantes y demandas que luego aparecerían como conquistas científicas.

La destacada condición simbólica del arte es precisamente el sine qua non del mismo. Sin símbolo, sin simbolización, no resulta posible ni la creación ni la experiencia estética. Paul Ricoeur (1990) nos permite clarificar esta noción de símbolo que referimos a la obra de arte, al definirlo como una expresión "de doble o múltiple sentido cuya textura semántica es correlativa del trabajo de interpretación que hace explícito su segundo sentido o sus sentidos múltiples" (p. 15).

Asimismo, de acuerdo a lo expresado por Ernst Cassirer en su Antropología Filosófica (1945), entendemos que la persona se define y se distingue no por ser un animal racional, sino por ser un animal simbólico; que percibe, piensa, da cuenta y transforma su realidad, a partir de la creación e interpretación simbólica. El lenguaje, el mito, el arte y la religión son considerados los "diversos hilos que tejen la red simbólica, la urdimbre complicada de la experiencia humana" (Cassirer, 1945, p. 47). Por tanto, solo mediante el largo rodeo de los símbolos, 
a través de formas lingüísticas, como el arte, la religión, la filosofía, y la ciencia, puede el hombre conocer(se) y dar a conocer. Desde aquí, Cassirer (1945) define el símbolo como el camino de la civilización.

En este camino de humanización, desde tiempos remotos, cuando las distintas civilizaciones comenzaron a mirar más allá de lo acostumbrado, a percibir lo indecible, lo inconmensurable, aquello que suscita el asombro, que instaura la duda donde antes anidaba una certeza heredada, los límites empezaron a resquebrajarse. Pero estos, necesariamente, deben reconstruirse. Es claro que, sin contención alguna, sin la existencia de demarcaciones, resultaría imposible erigir un mundo y convivir en él.

Por ello, a través de las producciones que hoy denominamos arte, religión, filosofía y ciencia —anudadas en mayor o en menor medida conforme cada tiempo y lugar-, el ser humano consigue acercarse a los límites, a esos cuestionamientos que más le interesan y más difíciles -o imposibles - le resultan responder; y, luego, traerlos al plano de lo decible, para enriquecer su mundo, su horizonte, sus posibles. De esta manera, problemáticas tales como el espacio, el infinito, el tiempo, la eternidad, lo sobrenatural, la vida, la muerte, aparecen paulatinamente vehiculizadas a través de las producciones simbólicas, a fin de llenar los vacíos que el individuo va descubriendo en su devenir.

En su existir en el mundo, en su hacer mundo, el existente humano es posibilidad, es proyecto. Pero este existir no es ilimitado, el tiempo de su hacerse no es infinito. Ese es su límite irrebasable: la posibilidad de morir que habita en todas las demás posibilidades.

Habitualmente, el individuo observa que otros mueren. Esos otros con los que convive, esos otros que tal vez se quedaron sin tiempo para consumir, o bien, los consumió el tiempo. Y entiende que también él morirá, aunque le guste pensar que aún no. No obstante, esa misma finitud que se oculta en la cotidianeidad, en un mundo ya interpretado por esos otros que nos condiciona $-\mathrm{y}$ a la vez nos permite-cualquier experiencia, logra ser develada a través de la creación artística.

La obra de arte, al desplegar un mundo habitable, con su propia lógica, nos sumerge en una experiencia en la cual nuestro modo habituado y domesticado de percibir no tiene competencia. La experiencia estética 
agrieta nuestros hábitos perceptuales y nos permite experimentar e interpelarnos acerca de aquellos posibles que en la cotidianeidad se enmascaran; configurando una experiencia de (auto)conocimiento mediante la cual, el existente humano encuentra la oportunidad de develar sus posibles, entre ellos, su propia finitud. No para arrojarse en el sinsentido, tampoco para abalanzarse a eventuales consuelos, sino para reconstruir desde esos límites — consciente de su situación-, una existencia más propia. La verdad resulta desocultada a través de la ficción.

Por tanto, como límite irrebasable, no es el finar una experiencia que puede hacerse cara a cara, y volver para narrarla. Su revelar, su indagar, debe ser mediatizado, indefectiblemente, a través de lo simbólico. En este desocultar la posibilidad de morir, la obra de arte le permite al individuo conquistar su propia muerte, comprender su temporalidad.

Al reconocer su finitud, la persona encuentra la posibilidad de descubrir cada momento como único e irrepetible, como una oportunidad de elegirse en su ser proyecto hasta la muerte. Es decir, comprenderse como un ser delimitado entre un nacimiento que no eligió y una muerte que no puede evitar; pero que, no obstante, desde el (re)conocimiento de sus límites y posibles, puede elegir un hacerse más auténtico, emancipado de los condicionamientos heredados que gobiernan su percepción cotidiana.

En relación con la experiencia del tiempo, Hans-Georg Gadamer [1977] (1991) distingue dos experiencias fundamentales. Por un lado, una experiencia práctica, de un tiempo que se divide para algo, un tiempo vacío que debe llenarse. El extremo de este tiempo sería un tiempo que atormenta, el aburrimiento. Pero también en este tiempo práctico uno puede llegar caer en el ajetreo, donde el tiempo es un tiempo para algo, para un plan. Es así como vamos ocupando el tiempo ocupándonos; llenando tiempos como compartimientos estancos, yuxtaponiendo momentos y fragmentando nuestra experiencia vital. Este es el tiempo en que, regularmente, nos encontramos siendo.

Por otro lado, el arte nos abre a una segunda experiencia del tiempo, que es también el tiempo de la fiesta. La ficción —en cuanto verosímiltiene sus propios códigos para ser experimentada. Así como el tiempo

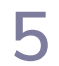


que hace a alguien viejo o joven no es el tiempo que calculamos con el reloj, sino que lo que se percibe ahí es un tiempo propio; al habitar el mundo de la obra, lo que experimentamos es el tiempo del arte (Gadamer, [1977] 1991). Un tiempo que nos permite percibir más allá de nuestra percepción domesticada; que la cuestiona, que disrumpe con sus propias exigencias. El arte nos libera y deja en suspenso el tiempo medible, el tiempo para algo. Nos invita a demorarnos en el tiempo de la obra, a habitar la obra, a vivir la fiesta. Es esta una experiencia disruptiva, que no trae calma, que no promete felicidad; sino que interpela en la posibilidad y nos sitúa fuera de los lugares comunes que habitamos.

En una hora puede pasar verosímilmente una vida, y así exige experimentarlo la obra de arte para poder efectivizar la experiencia estética. En la composición musical 4'33" (1952), de John Cage, no pasa solo tiempo cuantificable. No se trata de una estructura a priori para ser llenada. Es más que eso. Es ironía y ruptura de nuestras percepciones habituales del mundo, del tiempo, del sonido, del silencio. Es originalidad e irrepetibilidad, es enigma y certeza, opacidad y transparencia, es apertura.

Como quedó expresado anteriormente, la indagación existencial a través del arte acompañó al género humano, invariablemente, en su camino de humanización, en su dar(se) cuenta. Es por eso que podemos encontrar innumerables ejemplos de lo expuesto hasta aquí. Pero vale recordar a Jorge Luis Borges y su poema "Límites" (1974), para pensar cómo a través de la poética de la obra de arte, a través de la bella representación de aquello que suscita angustia, se nos sitúa —mediante la experiencia estética - frente a nuestra más propia posibilidad, la de morir:

De estas calles que ahondan el poniente,

Una habrá (no sé cuál) que he recorrido

Ya por última vez, indiferente

Y sin adivinarlo, sometido.

A Quién prefija omnipotentes normas

Y una secreta y rígida medida

A las sombras, los sueños y las formas

Que destejen y tejen esta vida. 
Si para todo hay término y hay tasa

Y última vez y nunca más y olvido

¿Quién nos dirá de quién, en esta casa,

Sin saberlo, nos hemos despedido?

Tras el cristal ya gris la noche cesa

$Y$ del alto de libros que una trunca

Sombra dilata por la vaga mesa,

Alguno habrá que no leeremos nunca.

Hay en el Sur más de un portón gastado

Con sus jarrones de mampostería

Y tunas, que a mi paso está vedado

Como si fuera una litografía.

Para siempre cerraste alguna puerta

$Y$ hay un espejo que te aguarda en vano;

La encrucijada te parece abierta

Y la vigila, cuadrifronte, Jano.

Hay, entre todas tus memorias, una

Que se ha perdido irreparablemente;

No te verán bajar a aquella fuente

Ni el blanco sol ni la amarilla luna.

[...] ¿Y el incesante Ródano y el lago,

Todo ese ayer sobre el cuál hoy me inclino?

Tan perdido estará como Cartago

Que con fuego y con sal borró el latino.

Creo en el alba oír un atareado

Rumor de multitudes que se alejan;

Son lo que me ha querido y olvidado;

Espacio y tiempo y Borges ya me dejan.

No es la intención realizar un análisis exhaustivo de este poema, sino rescatar sus interrogantes, sus cuestionamientos. Desde allí, podemos observar cómo el autor nos enfrenta a la inevitabilidad de una muerte inminente; $y$, con ello, al desconocimiento permanente $y$ angustiante que 
llevamos a cuestas de no saber cuándo será la última vez de cualquier acción. Nos muestra como seres irremediablemente sometidos a alguien que nos trasciende, y nos fija las normas — quizás la misma muerte, Dios, lo indecible-. Nos hace pensar en esa calle por la que ya nunca más transitaremos, reconocer que a alguien le hemos dado un adiós definitivo, y que un libro, que hemos dejado esperando, jamás leeremos. También nos expone los límites de nuestra capacidad de recordar y, por ende, de narrarnos, de entendernos; ya que irremediablemente hay recuerdos que perderemos para siempre. Es esta una pérdida tan imperiosa como irreparable. El olvido es necesario para el mortal, no le es conveniente —ni posible- recordar todo.

Luego de estas cavilaciones, Borges se presenta desdoblado, observándose a sí mismo, dejándose a sí mismo. Reconociendo el límite, que la vida inexorablemente termina, que la muerte se avecina permanentemente.

A través de este poema, al habitar el mundo de esta obra, se nos permite experimentar y develar como propios esos mismos límites irresolubles — dados por nuestra finitud- que el autor narra. Límites que en la cotidianeidad acostumbrada en la que convivimos, se enmascaran para contenernos como uno más.

En consecuencia, a través de la experiencia estética podemos entender cómo, en nuestra temporalidad, la muerte le imprime un valor especial y un sentido a cada momento, a cada lugar, a cada mirada. A cada momento, porque nos revela que puede ser el último; a cada lugar, porque siempre puede ser la última vez que lo habitemos; y a cada mirada, porque en ella puede albergarse un amor a última vista, un adiós definitivo.

El mismo Borges, en su cuento «El inmortal» (1974), nos presenta la importancia de estas experiencias fundacionales, las cuales, señala, se encuentran vedadas a los inmortales. En la eternidad que habita un inmortal, tarde o temprano repetirá cualquier situación hasta el hartazgo; beberá de todos los ríos, dado que él es eterno y la cantidad de ríos no es infinita. Para él nada puede ocurrir una sola vez, por eso lo elegíaco, lo grave y lo ceremonial no rige para los inmortales. Ellos no se dicen adiós. 
En virtud de sus posibles, los inmortales ven como seres patéticos a los mortales, como seres que se conmueven de su condición de fantasmas; ya que para un mortal cada acto puede ser el último, y todo entre ellos tiene el valor de lo irrecuperable y lo azaroso.

Podemos encontrar en las obras referidas aquellos interrogantes existenciales tan profundos como irresolubles que acompañaron a Borges durante su obra. Límites indagados hasta el agotamiento, búsqueda incesante del conocimiento.

Pero este bordear los abismos, la búsqueda de nuevos horizontes, esta ambición de aumento de mundo, debe ser vehiculizada y contenida a través de las producciones simbólicas — como las del arte-, para no caer en el precipicio sin retorno del deseo descontrolado. Como nos recuerda Eduardo Grüner (2001) — quien cita a Friedrich Nietzsche"tenemos el arte para defendernos de la muerte» (p. 27).

\section{A MODO DE CONCLUSIÓN}

El arte ha acompañado y amparado al existente humano en su erigirse, en su hacer e interpretar el mundo. No en forma de un acompañamiento hedonista ni complaciente, sino como producción que le permite indagar lo indecible, los límites, los abismos, y dar cuenta de ellos a través de lo simbólico, como un modo particular de dar(se) cuenta de sí y de su mundo.

Luego, en la experiencia estética, al habitar el mundo de la obra, encuentra la persona la oportunidad de develar aquellos posibles que en la cotidianeidad se encubren; $y$, así, consigue enriquecer su mundo; forjarse un horizonte más amplio de experiencias.

Si la posibilidad de morir es el límite irrebasable que nos constituye, y que en la cotidianeidad se oculta - y ocultamos-, la obra de arte permite experimentar más allá del tiempo cotidiano, y develar la misma. En la experiencia estética logramos revelar nuestra existencia como temporalidad y, de este modo, reconocer el valor de cada momento como una oportunidad para conquistar nuestra propio ser hasta la muerte. 
Ese es el dominio del arte, lo posible. Desde su indagar los límites, lo indecible, lo que nos angustia, aquello que permanece inaccesible al lenguaje articulado; la creación artística - a través de una representación simbólica-, procura traer lo percibido en los abismos al plano de lo decible, de lo experimentable; a fin de ampliar nuestra morada, de interpelarnos, de decir donde otros enmudecen.

Pues, en palabras de Rainer Maria Rilke (2001), «lo bello no es más que el comienzo de lo terrible que apenas podemos soportar».

\section{REFERENCIAS}

Borges, J. L. (1974). Obras Completas. Ciudad Autónoma de Buenos Aires, Argentina: Emecé.

Cage, J. (1952). 4'33" [Composición musical]. Recuperado de https:// www.youtube.com/watch? $v=g N 2 z c L B r_{-} V M$

Cassirer, E. (1945). Antropología filosófica. Ciudad de México, México: Fondo de Cultura Económica.

Gadamer, H. G. [1977] (1991). La actualidad de lo bello. Barcelona, España: Paidós.

Grüner, E. (2001). El sitio de la mirada. Ciudad Autónoma de Buenos Aires, Argentina: Norma.

Proust, M. [1927] (1994). En busca del tiempo recobrado. Quito, Ecuador: Libresa.

Ricoeur, P. (1990). Freud: Una interpretación de la cultura. Ciudad de México, México: Siglo Veintiuno.

Rilke, R. M. (2001). Las elegías del Duino y otros poemas. Santiago de Chile, Chile: Editorial Universitaria. 